\title{
PEPTIC ULCER IN TOWN AND COUNTRY
}

\author{
BY \\ C. N. PULVERTAFT \\ Gastric Clinic, County and City Hospitals, York
}

Striking geographical variations in the incidence of peptic ulcers have been reported from several countries. Dogra (1940) for instance, found peptic ulcer to be far more common in Southern than in Northern India, and Konstam (1954) reported a higher incidence in Southern than in Northern Nigeria.

These differences are not confined to large geographical areas, and in Great Britain, Morris and Titmuss (1944) demonstrated a lower mortality in rural than in urban communities, while Doll, Jones, and Buckatzsch (1951) reported a low incidence amongst agricultural workers. Similar trends have been reported from other countries, e.g. Bager (1929) in Sweden, Ginanneschi (1938) in Italy, and Alsted (1953) in Denmark.

Watkinson (1958a), in a planned study of autopsies performed between December, 1955, and November, 1956, in selected hospitals in England and Scotland, found a significantly higher incidence of duodenal ulcers in the North than in the South of England-a difference more marked in men than in women.

\section{Present Study}

A survey of the incidence of new cases of peptic ulceration-occurring in the City of York and the surrounding countryside was carried out in the 6 years, 1952-1957. The total population served by York is approximately $225-250,000$, but, owing to the overlap with other hospital areas, the present report is confined to the City of York and to a rural area to the north, south, and east of the city, which is served exclusively by York. The total population of York is 105,371, and of the country area 33,335.
The incidence has been related to the population aged 15 and over:-

\begin{tabular}{llll|c|c}
\hline \multicolumn{3}{c|}{ Area } & & Men & Women \\
\hline York &.. &.. &.. & 38,454 & 43,725 \\
Country &.. &.. &.. & 13,142 & 12,163 \\
\hline
\end{tabular}

METHOD.-During the 6 years, 1952-1957, every new patient diagnosed amongst the residents of this area has been recorded, even though the diagnosis was first made outside York; for instance, one patient suffered a perforation during a holiday in Sweden and another when on a visit to Toronto. A "new" patient is defined as one in whom the diagnosis has not previously been established. The review covers both hospital and private practice.

Any estimate of ulcer incidence is influenced by the criteria of diagnosis, in particular, of radiological diagnosis. For this reason, only those diagnoses that are beyond doubt, however made, have been accepted, and the estimates are, therefore, conservative. The criteria used in this study were:

(1) Acute perforation.

(2) Haemorrhage with demonstrable ulcer.

(3) Ulcers found at laparotomy or gastroscopy.

(4) Radiologically demonstrable ulcer.

(5) Ulcers found at autopsy (but only if this confirms a previously doubtful or negative radiological finding). Ulcers found incidentally in persons not known to have experienced symptoms are excluded, as it is felt this might give a false increase in the York figures as compared with the rural area. 
TABLE I

TOTAL NEW ULCERS DIAGNOSED 1952-1957 IN YORK AND COUNTRY

\begin{tabular}{|c|c|c|c|c|c|c|c|c|c|c|c|c|}
\hline \multirow{3}{*}{\multicolumn{2}{|c|}{$\frac{\text { Sex .. }}{\text { Site of Ulcer }}$}} & \multirow{3}{*}{$\frac{\cdots}{\cdots}$} & \multicolumn{5}{|c|}{ Men } & \multicolumn{5}{|c|}{ Women } \\
\hline & & & \multirow{2}{*}{ Duodenal } & \multicolumn{2}{|c|}{ Gastric } & \multirow{2}{*}{$\begin{array}{c}\text { Gastric } \\
\text { and } \\
\text { Duodenal }\end{array}$} & \multirow{2}{*}{ Total } & \multirow{2}{*}{ Duodenal } & \multicolumn{2}{|c|}{ Gastric } & \multirow{2}{*}{$\begin{array}{l}\text { Gastric } \\
\text { and }\end{array}$} & \multirow{2}{*}{$\begin{array}{l}\text { Duodenal } \\
\text { Total }\end{array}$} \\
\hline & & & & Body & Antrum & & & & Body & Antrum & & \\
\hline York & . & $\cdots$ & 546 & 109 & 27 & 8 & 690 & 165 & 73 & 11 & 5 & 254 \\
\hline Country & $\ldots$ & $\cdots$ & 112 & 17 & 4 & 0 & 133 & 39 & 16 & 0 & 0 & 55 \\
\hline Total & $\ldots$ & $\ldots$ & 658 & 126 & 31 & 8 & 823 & 204 & 89 & 11 & 5 & 309 \\
\hline
\end{tabular}

\section{RESULTS}

A total of 1,132 patients (823 men and 309 women) were diagnosed. The details of the type of ulcer are set out in Table 1 .

The symptoms leading to hospital attendance and diagnosis are shown in Table II; classification in the categories haemorrhage or perforation does not necessarily indicate the initial symptoms, as other symtoms may have been present previously without the patient seeking medical advice.

TABLE II

DISTRIBUTION PER CENT., BY SYMPTOMS LEADING TO PATIENTS' ATTENDANCE AT HOSPITAL

\begin{tabular}{|c|c|c|c|c|c|c|}
\hline Sex & . & .. & .. & . & Men & Women \\
\hline Clinical Symp & toms & . & $\ldots$ & $\ldots$ & $70 \cdot 5$ & $75 \cdot 7$ \\
\hline Haemorrhage & $\ldots$ & $\ldots$ & $\ldots$ & . & $15 \cdot 8$ & $16 \cdot 5$ \\
\hline Perforation & $\ldots$ & .. & .. & $\ldots$ & $13 \cdot 7$ & $7 \cdot 8$ \\
\hline
\end{tabular}

The percentage of women presenting with acute perforation ( 7.8 cent.) is appreciably less than the percentage of men ( 13.7 per cent.), probably because the ratio of duodenal to gastric ulcers is less in women $(2: 1)$ than in men $(4: 1)$.

These figures can be related to the population at risk and expressed as the mean annual incidence rates. The overall incidence per 1,000 aged 15 and over for men and women in the area on this basis was therefore:

\begin{tabular}{|c|c|c|c|c|}
\hline \multicolumn{3}{|c|}{ Site of Ulcer } & Men & Women \\
\hline $\begin{array}{l}\text { Duodenal } \\
\text { Gastric ... }\end{array}$ & & $\begin{array}{l}. . \\
. .\end{array}$ & $\begin{array}{l}2 \cdot 15 \\
0 \cdot 53\end{array}$ & $\begin{array}{l}0.62 \\
0.31\end{array}$ \\
\hline
\end{tabular}

When analysed on a town and country basis, the incidence of gastric and duodenal ulcers, in both sexes, was found to be higher in the town than in the country (Table III), the difference for men, but not for women, being statistically significant. This finding could possibly be due to the fact that country people were less complaining or less willing to see their own doctor or attend at a hospital for investigation. However, no such selection could affect the number of acute perforations occurring in this area, because these are all referred to York.

The ratio between the incidence of acute perforated duodenal ulcers (old and new patients) in York and the country area was the same as that for all duodenal ulcers (Table III) $1 \cdot 7: 1$. This difference between town and country is, therefore, in all probability, real.

The difference, at least for male duodenal ulcers, was more marked in the 2 years, 1952-1953, than in

TABLE III

MEAN ANNUAL INCIDENCE OF ULCERS IN YORK AND COUNTRY

\begin{tabular}{|c|c|c|c|c|c|c|c|c|c|c|}
\hline & \multirow{2}{*}{ Sex } & & \multirow{2}{*}{\multicolumn{3}{|c|}{ Type of Ulcert }} & \multicolumn{2}{|c|}{$\begin{array}{l}\text { Mean Annual Incidence Rate per } \\
1,000\end{array}$} & \multirow{2}{*}{$\begin{array}{c}\text { Ratio } \\
\text { York : Country }\end{array}$} & \multicolumn{2}{|c|}{ Significance of Difference } \\
\hline & & & & & & York & Country & & $x^{2}$ & \\
\hline \multirow{2}{*}{ Men } & & \multirow{2}{*}{$\cdots$} & Duodenal & $\cdots$ & $\cdots$ & $2 \cdot 40$ & $1 \cdot 42$ & $1 \cdot 7: 1$ & $26 \cdot 25$ & $p<\cdot 001$ \\
\hline & & & Gastric* & $\cdots$ & $\cdots$ & 0.62 & $0 \cdot 27$ & $2 \cdot 3: 1$ & $14 \cdot 08$ & $p<\cdot 001$ \\
\hline \multirow{2}{*}{ Women } & \multirow{2}{*}{$\cdots$} & \multirow{2}{*}{. } & Duodenal & $\cdots$ & $\cdots$ & 0.65 & 0.53 & $1 \cdot 2: 1$ & $1 \cdot 19$ & $\cdot 2<p<\cdot 3$ \\
\hline & & & Gastric* & $\cdots$ & $\cdots$ & $0 \cdot 34$ & $0 \cdot 22$ & $1 \cdot 5: 1$ & $2 \cdot 66$ & $\cdot 1<p<\cdot 2$ \\
\hline
\end{tabular}

- Gastric includes ulcers of the body of the stomach and of the antrum.

t Double active ulcers and included in both categories (duodenal and gastric). 
1956-1957 (Table IV), this being due to a decline in male duodenal ulcers in York, whereas the incidence remained constant in the country. The diminution in York was apread over all social orders and all age groups, but was more marked in patients with short histories ( 1 to 2 years) than in those with long histories ( 5 years or more). For this reason, it is unlikely that the 1952-1953 rate was abnormally high because patients, not previously investigated, took advantage of the easier diagnostic facilities in the

TABLE IV

COMPARISON OF MEAN ANNUAL INCIDENCE RATE PER THOUSAND AT RISK OF MALE DUODENAL ULCERS IN TOWN AND COUNTRY FOR THE TWO YEARS,

1952-53 and 1956-57

\begin{tabular}{c|c|c|c}
\hline Year & York & Country & $\begin{array}{c}\text { Ratio } \\
\text { York : Country }\end{array}$ \\
\hline $1952-3$ & $2 \cdot 76$ & $1 \cdot 33$ & $2 \cdot 1: 1$ \\
\hline $1956-7$ & $1 \cdot 82$ & $1 \cdot 37$ & $1 \cdot 3: 1$ \\
\hline
\end{tabular}

early years of the National Health Service. Again, the total acute perforation rate (old and new patients) for duodenal ulcers in York showed a similar decline from 0.55 to 0.29 per thousand at risk.

In the latter part of this period, the incidence in some of the country parishes was already as high as in the town, so it may well be that no difference between town and country could now be demonstrated in other parts of Britain.

The incidence of gastric ulcers in men, and of both gastric and duodenal ulcers in women, showed no such decline and remained almost constant.

INCIDENCE AND AGE.-The difference between town and country could not be due to a different age distribution between the two populations as it was demonstrable at all ages (Fig. 1). The findings for gastric ulcers in men and for both gastric and duodenal ulcers in women confirm this trend, but are less reliable because the numbers are small.

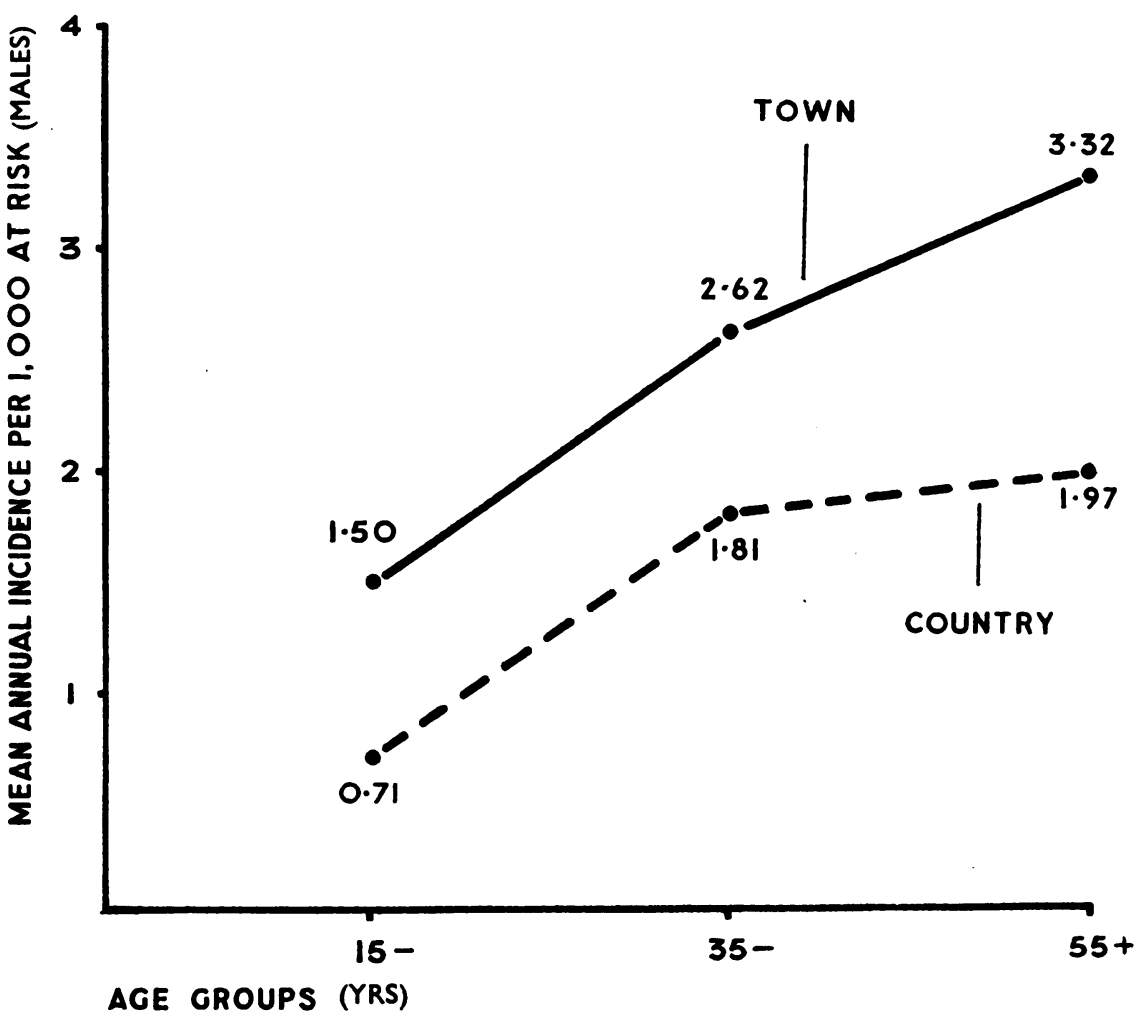

FIG. 1.-Comparative incidence of male duodenal ulcers for town and country, by age. 
Age is, however, important in relation to incidence. The age distribution of ulcers in the City of York shows that the highest numbers of both duodenal ulcers (Table V, and Fig. 2, opposite) and gastric ulcers (Table VI, and Fig. 3, opposite) in men were diagnosed in the 45 to 54-year age group, but when these figures were related to the numbers at risk, the highest incidence for both was seen in the 55 to 64-year age group.

This, however, only indicates the age incidence at diagnosis, not the age when symptoms first occur; the latter is more difficult to assess owing to the often insidious onset of symptoms.

Furthermore, there is the additional inaccuracy of relating such figures to the present age distribution of the population, Any assessment, therefore, can only be approximate. Allowing for these inaccuracies; the finding shown in Fig. 2 suggests that in men there is an equal liability for a duodenal ulcer to start at any age from 25 to 64 years, but that the risk before age 25 and after age 65 is somewhat less. On the other hand, gastric ulcers (body of stomach only) show a peak incidence of onset of symptoms in the 45 to 54 and 55 to 64-year age groups.
In women, the largest number of duodenal ulcers was diagnosed in the 45 to 54-year age group, and this was also the peak incidence when related to the numbers at risk. In contradistinction to male duodenal ulcers, there was a peak for the onset of symptoms in females in the 35 to 44-year group. The number of gastric ulcers diagnosed was the same for the three oldest age groups the highest incidence in relation to population at risk coming in the 55 to 64-year group, with only a slight fall in the $65+$ age group. The peak age for onset of symptoms is 45 to 54 years.

These findings suggest that age is a factor in the incidence of male gastric ulcers, and in both duodenal and gastric ulcers in women, but is less significant in male duodenal ulcers.

INCIDENCE AND Social Class.-Doll and others (1951) showed that social status, by itself, had no influence on the incidence of duodenal ulcers, but that gastric ulcers were more common among semiskilled workers than among members of the higher social orders.

TABLE V

AGE DISTRIBUTION OF DUODENAL ULCERS IN THE CITY OF YORK, 1952-57

\begin{tabular}{|c|c|c|c|c|c|c|c|c|c|c|}
\hline \multirow{3}{*}{\multicolumn{2}{|c|}{ Age (yrs) }} & & \multicolumn{4}{|c|}{ Number of Cases } & \multirow{2}{*}{\multicolumn{4}{|c|}{$\frac{\text { Mean Annual Incidence Rates per } 1,000}{\text { Men }}$}} \\
\hline & & & \multicolumn{2}{|c|}{ Men } & \multicolumn{2}{|c|}{ Women } & & & & \\
\hline & & & Diagnosis & Onset & Diagnosis & Onset & Diagnosis & Onset & Diagnosis & Onset \\
\hline & & & $\begin{array}{r}36 \\
88 \\
95 \\
137 \\
111 \\
74\end{array}$ & $\begin{array}{r}57 \\
120 \\
111 \\
94 \\
74 \\
40\end{array}$ & $\begin{array}{l}7 \\
21 \\
42 \\
47 \\
25 \\
23\end{array}$ & $\begin{array}{l}16 \\
26 \\
44 \\
33 \\
15 \\
15\end{array}$ & $\begin{array}{r}.93 \\
1.97 \\
2.02 \\
3.21 \\
3.69 \\
2.75\end{array}$ & $\begin{array}{l}1 \cdot 43 \\
2.68 \\
2.37 \\
2.20 \\
2.47 \\
1.48\end{array}$ & $\begin{array}{r}.17 \\
.44 \\
.83 \\
1.03 \\
.68 \\
.63\end{array}$ & $\begin{array}{l}.37 \\
.55 \\
.87 \\
.71 \\
.40 \\
.38\end{array}$ \\
\hline All Ages & $\cdots$ & . & 542 & $496^{*}$ & 165 & $149^{*}$ & $2 \cdot 35$ & $2 \cdot 15$ & 0.63 & .57 \\
\hline
\end{tabular}

- These totals are less than the corresponding numbers diagnosed because of the omission of patients in whom the history of illness was unreliable, or in whom the onset occurred before age 15 .

TABLE VI

AGE DISTRIBUTION OF GASTRIC ULCERS (BODY OF STOMACH ONLY) IN THE CITY OF YORK, 1952-57

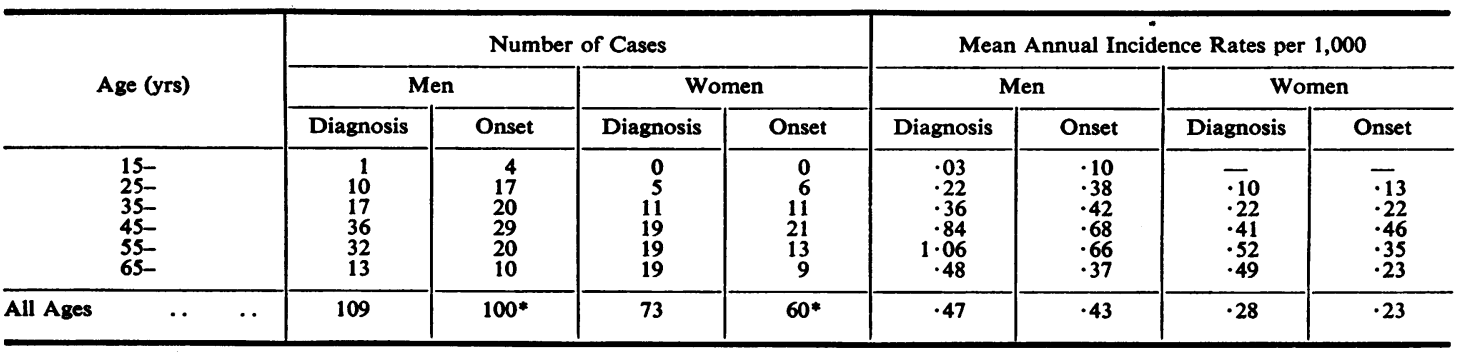

* These totals are less than the corresponding numbers diagnosed because of the omission of patients in whom the history of illness was unreliable, or in whom the onset occurred before age 15 . 


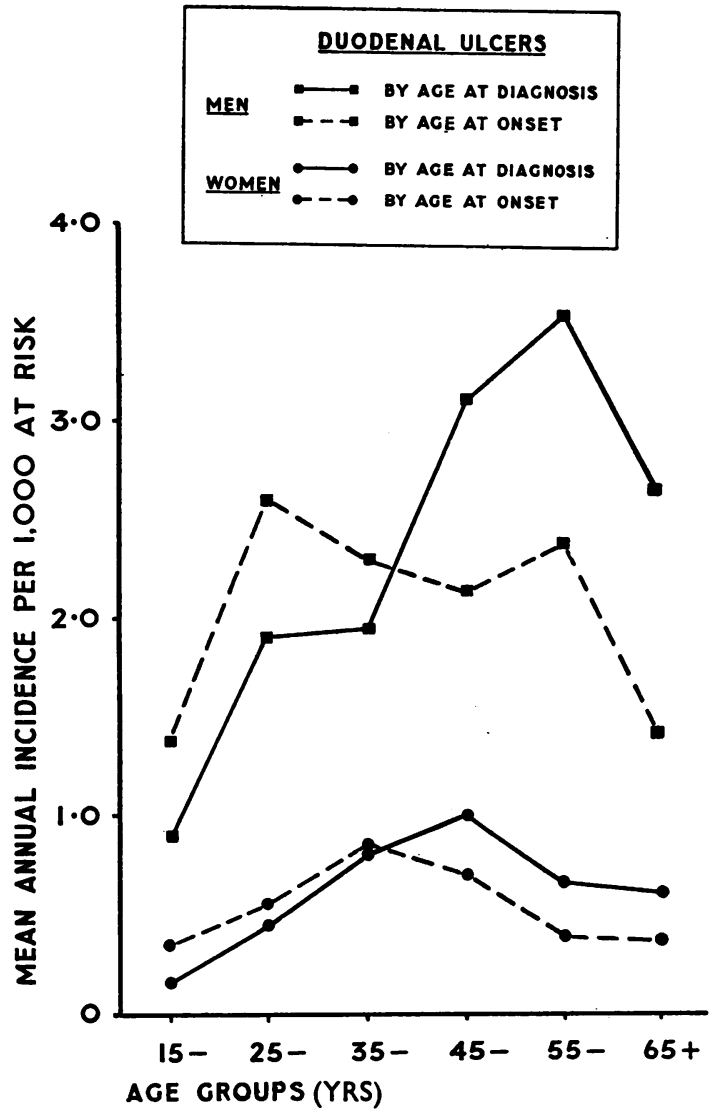

FIg. 2.-Distribution of duodenal ulcers for the City of York, by sex, age at diagnosis, and age at onset. Patients under 15 at diagnosis are omitted.

To date, it has not been possible to study the influence of specific occupations, but the overall incidence for different social groups (General Register Office, 1956) gives results similar to those reported by Doll and others (Table VII).

\section{TABLE VII}

MEAN ANNUAL INCIDENCE PER 1,000 AT RISK BY SOCIAL CLASS

\begin{tabular}{|c|c|c|c|c|c|}
\hline \multirow{2}{*}{\multicolumn{3}{|c|}{ Type of Ulcer }} & \multicolumn{3}{|c|}{ Social Class } \\
\hline & & & $\begin{array}{c}\text { I and II } \\
\text { Professional } \\
\text { and Semi- } \\
\text { professional }\end{array}$ & $\begin{array}{c}\text { III } \\
\text { Skilled }\end{array}$ & $\begin{array}{c}\text { IV and V } \\
\text { Semi-skilled } \\
\text { and } \\
\text { Unskilled }\end{array}$ \\
\hline Duodenal & . & . & $2 \cdot 08$ & $2 \cdot 26$ & $3 \cdot 13$ \\
\hline Gastric* & $\ldots$ & $\ldots$ & $0.34(0.30)$ & $0.60(0.48)$ & $0.92(0.78)$ \\
\hline
\end{tabular}

* The figures in brackets for gastric ulcers are for ulcers of the body of the stomach only.
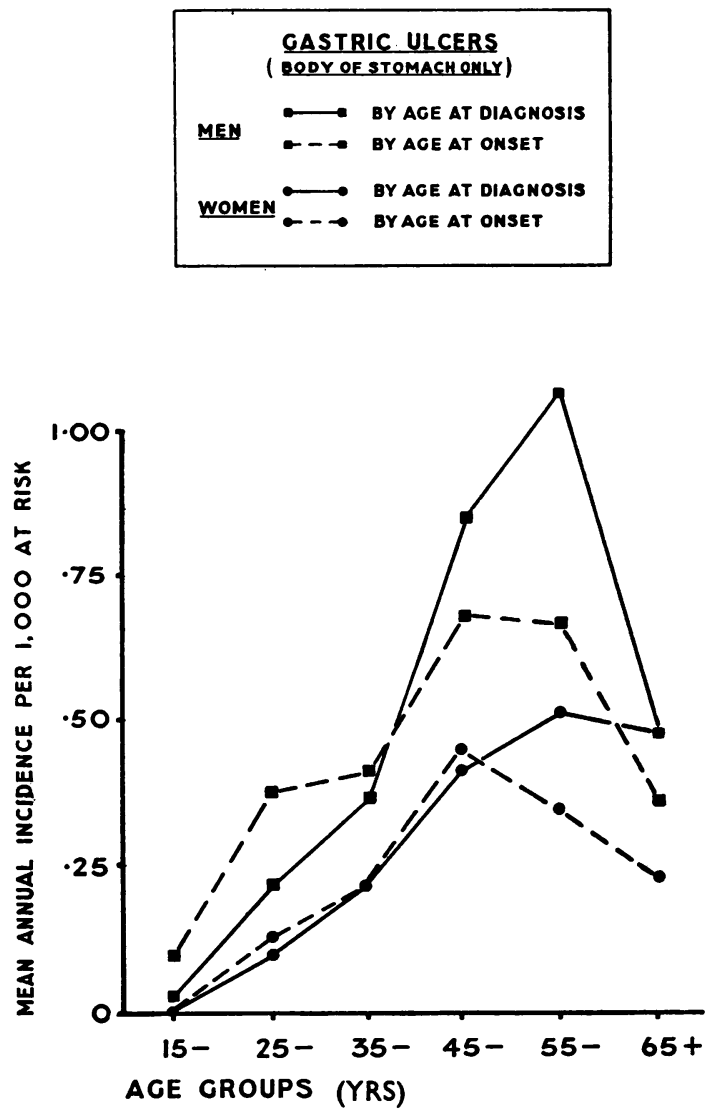

Fig. 3.-Distribution of gastric ulcers (body of stomach only) for the City of York, by sex, age at diagnosis, and age at onset. Patients under 15 at diagnosis are omitted.

Gastric ulcers are significantly more common in the semi-skilled and unskilled workers than in the skilled artisans $(p<\cdot 02)$ or professional and semiprofessional classes $(p<\cdot 01)$. The York figures, however, suggest that duodenal ulcers showed a similar trend, the differences between the semi-skilled and unskilled workers on the one hand and the higher social classes on the other being significant $(p<\cdot 01)$.

The country area is too small to consider in the various social orders; comparison is, therefore, confined to agricultural (Order 11, Sub-order 1) and all "other" occupations. The proportion of "other" to agricultural occupations is appreciably higher in the lower age groups (15 to 34 years= $1 \cdot 8: 1)$ than in the older age groups (55 years and over $=1 \cdot 2: 1)$; for this reason, direct comparison is confined to men aged 35 and over. It has, moreover, to be limited to part of the country area (Rural Districts of Easingwold and Pocklington), as the age 
distribution and occupation figures are not available for the rest of the area; this results in the rates appearing slightly higher than those shown in Fig. 1. For this area and age group, the mean annual incidence rates of duodenal ulcer per thousand at risk are almost identical:

$\begin{array}{lllll}\text { Agricultural Work } & . & \ldots & . . & 1.99 \\ \text { All Other Occupations } & \ldots & \ldots & . & 2.05\end{array}$

\section{COMPARISON OF INCIDENCE IN YORK WITH THAT IN}

\section{Other Parts of Great Britain}

It is notoriously difficult to compare clinical estimates of ulcer incidence with autopsy findings, and even with other clinical estimates, as the methods of study and reporting vary from centre to centre. Certain limited comparisons are, however, possible.

\section{(a) Acute Perforation in Glasgow, Aberdeen, and York}

The total perforation rate (old and new patients, gastric and duodenal ulcers) for the City of York, 1952-1953, can be compared with the figures for the same years in Glasgow given by Jamieson (1955). The annual rates per 100,000 population were:

\begin{tabular}{|c|c|c|c|}
\hline \multicolumn{2}{|c|}{ City } & Men & Women \\
\hline $\begin{array}{l}\text { Glasgow . } \\
\text { York }\end{array}$ & $\ddot{.}$ & $\begin{array}{l}32 \cdot 6 \\
26 \cdot 6\end{array}$ & $\begin{array}{l}3 \cdot 2 \\
2 \cdot 8\end{array}$ \\
\hline
\end{tabular}

It would appear that acute perforations in men and women were rather more common in Glasgow than in York.

Weir (1958), studying acute perforated ulcers in Aberdeen for the years 1946-57, found the average yearly incidence for duodenal ulcers in men to be 0.86 per 1,000 men aged 15 and over, which is about twice the rate of 0.41 in York for the years 1952-57. Perforated gastric ulcers in men were, however, less common in Aberdeen than in York.

The method of recording in Aberdeen and York may differ, in that an ulcer near the pylorus might be regarded as duodenal in Aberdeen and as prepyloric gastric in York. If, however, all those recorded as prepyloric in York are considered as duodenal, the difference, though slightly smaller, still exists.

\section{(b) Autopsy Findings in Leeds}

Watkinson (1958a), in his National Autopsy Survey for the years 1955 to 1956 , found that duodenal ulcers in men were slightly more common in York ( 7.4 per cent. active and healed ulcers) than in Leeds (6. 3 per cent.), the figures being corrected for age distribution. On the other hand, gastric ulcers were more common in Leeds ( 3.9 per cent.) than in York ( $2 \cdot 3$ per cent.).

Watkinson (1958b) also analysed the records of 12,640 autopsies performed in Leeds between 1930 and 1949.

Fig. 4 (opposite) shows for Leeds the rates for active chronic ulcers found incidentally at autopsy, excluding ulcer deaths, probably the best estimate of incidence in the general population. For York, Fig. 4 shows the rates for new cases diagnosed clinically. Patients with both duodenal and gastric ulcers have been included in both series of rates, and those with antral ulcers have been included in the gastric group.

The rates for York in Fig. 4 therefore differ slightly from those given in Table $\mathrm{V}$ and VI and Figs 2 and 3. Bearing in mind that the figures for York represent new cases only, and those for Leeds the total ulcer population, old and new patients, the correlation for duodenal ulcers is good, but gastrice ulcers are seen to be appreciably less common in York. This might well represent a failure of diagnosis in York, but it also corresponds with the finding of the National Autopsy Survey. This difference, if confirmed, cannot be explained simply by social class distribution, which is similar in the two cities.

\section{(c) Comparative Incidence in York and in the South of England}

Doll and others (1951), in a social study carried out in the south of England, estimated the annual risk of males aged 10 and over developing a peptic ulcer as $\mathbf{0 . 2 0 7}$ per cent. A comparative figure for York and District for the years 1952 to 57 is 0.258 per cent.

Such comparisons could well be extended, but these few examples illustrate both similarities and differences in the incidence, further study of which might help in understanding the aetiology of peptic ulcers.

\section{Discussion}

It would appear that, even in a small geographical area, there is a real and significant difference in incidence between town and country. There are indications, however, that this difference is disappearing, and already in some rural parishes the incidence is at least as high as in the town. 


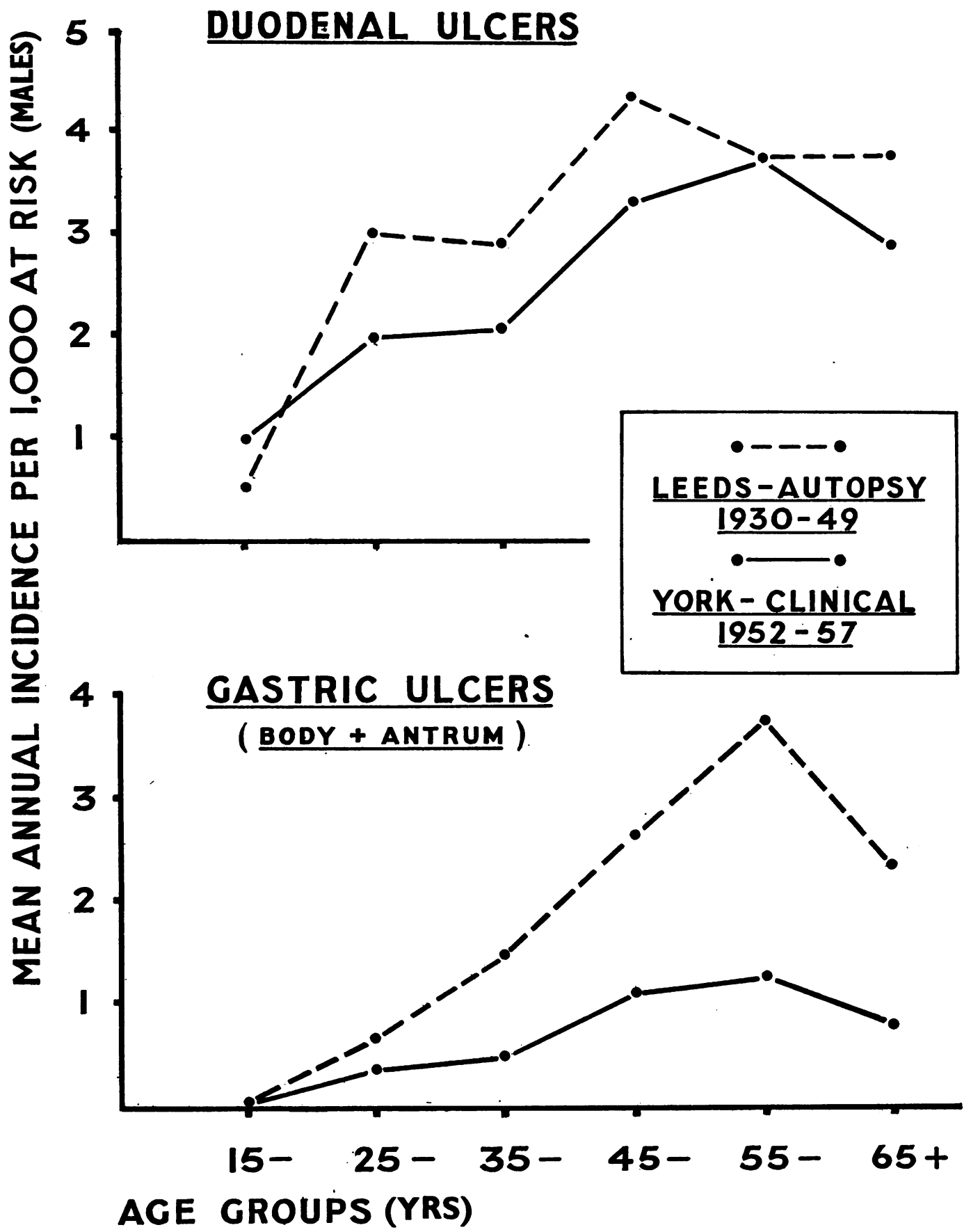

FIo. 4.-Comparative incidence of male duodenal ulcers and all male gastric ulcers in Leeds and York. The Leeds figures are for chronic active ulcers found incidentally at autopsy, excluding ulcer deaths (Watkinson). The York figures give a clinical estimate of new patients diagnosed in the years 1952-57.

Double active ulcers are included under both duodenal and gastric. 
The cause is a matter for speculation, and the simple explanation that it represents the increased stress of urban life is difficult to prove or disprove. It is doubtful, in this instance, if there is any fundamental difference in the tempo of life of the urban and rural communities, since York has a high standard of living and is neither very large nor highly industrialized.

It is possible that certain conditions of work (e.g. shift work) or some difference in daily habits (e.g. the time of meals, the type of food eaten, or the prevalence of smoking) may act as aggravating factors, leading to a higher incidence in the town. In this connexion, it is noteworthy that in recent years there has been a drift of labour from the land to urban occupations; this has led to the adoption of urban habits, even though the people still live in the country. Time alone will show whether this trend influences the incidence of peptic ulcers in rural districts.

\section{SUMMARY}

The incidence of new cases of peptic ulcer has been studied in York and environs for the years 1952 to 1957.

It has been found that in men both gastric and duodenal ulcers are significantly more common in the City of York than in the surrounding countryside. Similar differences have been observed for women, but these are not statistically significant.

Comparisons with other estimates of the incidence of peptic ulcers have yielded the following results:

(1) Acute perforated peptic ulcers in the years
1952-53 were more common in Glasgow than in York.

(2) The rate for male duodenal ulcers in Leeds is similar to that in York, but there are indications that gastric ulcer in men is more common in Leeds than in York.

(3) The estimated annual risk of males aged 10 years and over developing a peptic ulcer in York and district is 0.258 per cent., whereas Doll and others (1951) give a figure of $0 \cdot 207$ per cent. for southern England.

I am very grateful to all my colleagues-in particular to Mr. J. H. Conyers, Mr. R. A. Hall, Mr. J. K. WillsonPepper, and Dr. D. Laing, whose co-operation made this investigation possible; to the many general practitioners who have referred patients for investigation; to Dr. F. Avery Jones and Dr. Richard Doll for much helpful advice and encouragement; to Dr. Geoffrey Watkinson and Dr. R. D. Weir for allowing me to quote unpublished figures; to Mrs. R. Nicolson for careful record keeping, and to the York Peptic Ulcer Research Trust for financial assistance.

\section{REFERENCES}

Alsted, G. (1953). "Peptic Ulcer in Denmark, Copenhagen, 1953". Lancet, 2, 444 (Annotation).

Bager, B. (1929). Acta chir. scand., 64, Suppl. 11.

Dogra, J. R. (1940). Indian J. med. Res., 28, 145.

Doll, R., Jones, F. A., and Buckatzsch, M. (1951). Spec. Rep. Ser. med. Res. Coun. Lond., No. 276. H.M.S.O., London.

General Register Office (1956). "Census 1951. Classification of Occu-

pations". H.M.S.O., London.
Ginanneschi, G. (1938). Med d. Lavoro, 29, 65.

Ginanneschi, G. (1938). Med d. Lavoro, 29, 65.
Jamieson, R.A. (1955). Brit. med. J., 2, 222.

Konstam, P. G. (1954). Lancet, 2, 1039.

Morris, J. N., and Titmuss, R. M. (1944). Ibid., 2, 841.

Watkinson G. (1958a). Schweiz. Z. allg. Path., 21, 405.

(1958b). Personal communication.

Weir, R. D. (1958). Personal communication. 